\title{
Influence of drinking water containing Aloe vera (Aloe barbadensis Miller) gel on growth performance, intestinal microflora, and humoral immune responses of broilers
}

\author{
Meisam Shokraneh ${ }^{1}$, Gholamreza Ghalamkari², Majid Toghyani² and Nasir Landy ${ }^{1}$
}

1. Young Researchers and Elite Club, Isfahan (Khorasgan) Branch, Islamic Azad University, Isfahan 8155139999, Iran;

2. Department of Animal Science, Isfahan (Khorasgan) Branch, Islamic Azad University, Isfahan 8155139999, Iran.

Corresponding author: Meisam Shokraneh, e-mail: mei.shok@gmail.com,

GG: gh.ghalamkari@gmail.com, MT: toghiani@hotmail.com, NL: n_landy1984@yahoo.com

Received: 15-06-2016, Accepted: 29-09-2016, Published online: 05-11-2016

doi: 10.14202/vetworld.2016.1197-1203 How to cite this article: Shokraneh M, Ghalamkari G, Toghyani M, Landy N (2016) Influence of drinking water containing Aloe vera (Aloe barbadensis Miller) gel on growth performance, intestinal microflora, and humoral immune responses of broilers, Veterinary World, 9(11): 1197-1203.

\begin{abstract}
Aim: The risk of bacteria resistance to specific antibiotics possibly by continuous subtherapeutical administration of antibiotic growth promoters (AGPs) in poultry feed led to a ban on the use of AGP in poultry production. As a result of this ban, alternative substances for poultry growth promotion and disease prevention are being investigated, among which phytogenic and herbal products have received increased attention as natural additives because they have been accepted by consumers as natural additives. The effect of water supplementation of Aloe vera (AV) as an AGP substitute on performance, intestinal microflora, and immune responses of broilers.

Materials and Methods: The five experimental treatments were allocated to four replicates. The following treatments were applied (1) a basal broiler diet (C) and normal drinking water, (2) $0.5 \% \mathrm{AV}$ gel in drinking water, (3) $0.75 \% \mathrm{AV}$ gel in drinking water, (4) $1 \% \mathrm{AV}$ gel in drinking water, and (5) diet C supplemented with flavophospholipol at $4.5 \mathrm{mg} / \mathrm{kg}$ and drinking normal water. Vaccines against influenza disease and sheep red blood cell (SRBC) were administrated to immunological stimuli. The populations of Lactobacilli spp. and coliforms were enumerated in ileum.

Results: Body weight of broilers supplemented with different levels of AV increased compared with control group ( $\mathrm{p}<0.05)$. Birds supplemented with antibiotic had the best feed-to-gain ratio (F:G) in different periods. Supplementation of $0.5 \%$ and $0.75 \% \mathrm{AV}$ improved $\mathrm{F}: \mathrm{G}$ entire experimental period compared with control group $(\mathrm{p}<0.05)$. Coliform bacteria were reduced in broilers supplemented with different levels of AV or antibiotic $(\mathrm{p}<0.05)$. The Lactobacilli spp. population in birds supplemented with $0.75 \%, 1 \% \mathrm{AV}$ or antibiotic significantly was higher than other groups $(\mathrm{p}<0.05)$. Supplementation with $1 \% \mathrm{AV}$ led to greater antibody titers against SRBC compared with other groups $(\mathrm{p}<0.05)$.
\end{abstract}

Conclusion: These findings demonstrated a possibility of supplementing broiler drinking water with $1 \% \mathrm{AV}$ gel as an alternative for AGP substitution.

Keywords: Aloe vera gel, broiler, ileal microflora, immune responses, performance.

\section{Introduction}

So far, subtherapeutic dosage of antibiotics has been used more than 50 years in poultry nutrition to promote growth performance and prevent diseases [1-4]. However, continuous use of in-feed antibiotics is suspected to result in common problems such as increasing resistance of pathogens to antibiotics [5], accumulation of antibiotic residues in animal products and the environment [6,7], and imbalance of normal microflora [8]. Thus, efforts have been made to substitute antibiotic growth promoters (AGPs) with possible alternative growth promoters. Phytogenic and herbal products have received increased attention as natural additives in recent years because

Copyright: Shokraneh, et al. Open Access. This article is distributed under the terms of the Creative Commons Attribution 4.0 International License (http://creativecommons.org/licenses/ by/4.0/), which permits unrestricted use, distribution, and reproduction in any medium, provided you give appropriate credit to the original author(s) and the source, provide a link to the Creative Commons license, and indicate if changes were made. The Creative Commons Public Domain Dedication waiver (http:// creativecommons.org/publicdomain/zero/1.0/) applies to the data made available in this article, unless otherwise stated. they have been accepted by consumers as natural additives [9-12].

Aloe vera (AV) (Aloe barbadensis Miller) is a well-known medicinal herb and it has been used for commercial and therapeutic properties in many parts of the world [13]. It is a tropical plant of the genus Aloe and belongs to the Liliaceae family. AV gel contains compounds with proven antibacterial, antiviral, antifungal, antioxidant, anti-inflammatory, anti-diabetic, immunomodulatory, and wound healing properties [14]. AV gel contains acemannan, which has been identified as the primary polysaccharide $[14,15]$. Polysaccharides can affect the humoral immune response and cellular immunity [16]. Studies showed that acemannan is able to activate of macrophages to release inflammatory cytokines such as interleukin-1 (IL-1), IL-6, and tumor necrosis factor- $\alpha$ (TNF- $\alpha)[17,18]$. AV gel has demonstrated antimicrobial properties against a wide range of pathogenic bacteria such as Staphylococcus aureus and Escherichia coli $[19,20]$.

Darabighane and Nahashon [21] observed the beneficial influence of $\mathrm{AV}$ gel on intestinal microflora 
and immunity in broiler chickens. Furthermore, Feng et al. [22] reported positive effects of AV relative weight of lymphoid organs of broilers. Despite these findings, few studies have evaluated efficiency of AV on performance, intestinal microflora, and immune responses in broilers. The aim of this trial was to further enhance our knowledge and examine the effects of AV gel on broiler growth performance and other important biomarkers for broiler development and health such as carcass characteristics, ileal microflora, and humoral immunity when it is supplemented in drinking water.

\section{Materials and Methods}

\section{Ethical approval}

The animals were rared in accordance with the U.S. National Institutes of Health Guide for the Care and Use of Laboratory Animals. Furthermore, all procedures complied with the ethical guidelines of the Isfahan University's Ethical Committee, Islamic Azad University, Isfahan Branch, Iran (approval ref no. 2014-854).

\section{Plant material}

Fresh Aloe leaves were collected from botanical garden for the extraction of gel. The leaves were cleaned with water and the Aloe gel was extracted from the leaf manually by making a cut. Latex of the leaf was removed, and gel was collected in a beaker. A $10 \%(\mathrm{w} / \mathrm{v})$ concentrated infusion was prepared by taking $100 \mathrm{~g}$ of fresh gel in a glass bottle, and a liter of hot boiled distill water was poured on it. The bottle was shacked for 5-7 min to ensure thorough mixing and was then kept for 6-8 $\mathrm{h}$ at room temperature before use. The chemical characterization of the AV gel is provided in Table-1.

\section{Birds and experimental treatments}

Procedures performed in this trial were reviewed and approved by the Animal Care Committee of University of Isfahan. 240 1-day-old as hatched broilers (Ross 308) were purchased from a local hatchery. Broilers were individually weighed and randomly allotted to 5 experimental treatments for 6 weeks. Each treatment had 48 broilers which were arranged in 4 replicates of 12 broilers each. The following treatments were applied: (1) Basal broiler diet (C) and normal drinking water, (2) $0.5 \% \mathrm{AV}$ gel in drinking water, (3) $0.75 \%$ AV gel in drinking water, (4) $1 \%$ AV gel in drinking water, and (5) basal diet supplemented with flavophospholipol at $4.5 \mathrm{mg} / \mathrm{kg}$ and normal drinking water. The broilers received a corn-soybean meal basal

Table-1: Chemical characterization of AV gel.

\begin{tabular}{lc}
\hline Parameters & Content, \% \\
\hline Moisture & 98.5 \\
$\mathrm{pH}^{1}$ & 4.53 \\
Glucomannan & 0.05 \\
Polimanosa & 0.72 \\
\hline
\end{tabular}

${ }^{1} \mathrm{pH}$ is dimensionless. $\mathrm{AV}=$ Aloe vera diet (Table-2) formulated to meet or exceed the nutrient requirements of Ross 308 [23]. The chicks were fed a starter diet from 0 to 14 days, a grower diet from 15 to 28 days, and finisher diet from 29 to 42 days. All diets were in mash form. There was no coccidiostat added to the basal diet. Each replicate was assigned to a clean floor pen $(120 \mathrm{~cm} \times 120 \mathrm{~cm})$, and birds were raised on wood shavings. Ventilation was provided by negative pressure with fans. Heat was provided by gas-fired brooders; water and feed were offered ad libitum. The lighting program consisted of a period of $23 \mathrm{~h}$ light and $1 \mathrm{~h}$ of darkness. The ambient temperature in the experimental house was maintained at $32^{\circ} \mathrm{C}$ during the $1^{\text {st }}$ week and gradually decreased by $3{ }^{\circ} \mathrm{C} /$ week, and finally fixed at $22^{\circ} \mathrm{C}$ thereafter.

\section{Performance and carcass components}

Body weights (BW) of broilers were determined at $1,14,28$, and 42 days of age. Daily weight gain, daily feed intake (DFI), and daily water consumption were recorded in different growth periods, and the feed-to-gain $(\mathrm{F}: \mathrm{G})$ was calculated. All mortalities were removed from the pens and recorded during the experiment. At 42 days of age, two birds per replicate were chosen, based on the average weight of the group and slaughtered through cutting carotid arteries and partial slicing of the neck. Carcass yield was calculated by dividing eviscerated weight by live weight. The proventriculus, gizzard, heart, liver, and abdominal fat were removed, weighed, and calculated as percentages of live weight.

\section{Microbial analysis}

Ileal contents (from Meckel's diverticulum to the ileocecal junction) were collected from the slaughtered birds. The samples were placed in ice and thereafter sent to the microbiology laboratory for bacteriological analysis. $1 \mathrm{~g}$ sample was taken from each bird's ileal contents and blended with $9 \mathrm{~mL}$ of sterilized physiological saline solution and homogenized by a shaker. These suspensions were serially diluted to $10^{-7}$ using sterilized physiological saline solution. Appropriate dilutions were subsequently plated on duplicate selective agar media for enumeration of target bacterial groups. The selective media used for microbial culture were Macconkey agar (Merck) for coliforms and de Man Rogosa Sharp agar (CM0361, Oxoid Limited Kingdom) for Lactobacilli spp. The selective media for the microbial counts of coliform were incubated aerobically at $37^{\circ} \mathrm{C}$ for $24 \mathrm{~h}$. The agar plates for the counts of Lactobacillus were incubated in aseptic anaerobic jars at $37^{\circ} \mathrm{C}$ for $48 \mathrm{~h}$. The total colony count was then calculated as the number of colonies by reciprocal of the dilution. The microbial counts were expressed as $\log _{10}$ colony forming units per gram $\left(\log _{10} \mathrm{cfu} / \mathrm{g}\right)$ of sample [24].

\section{Immunity}

The commercially available oil-adjuvant injectable emulsion against Newcastle Disease virus (NDV), and avian influenza virus (AIV) was used (H9N2 
Table-2: The ingredient and calculated composition of basal starter, grower, and finisher diets (as-fed basis).

\begin{tabular}{|c|c|c|c|}
\hline Item & Starter (days 1-14) & Grower (days 15-28) & Finisher (days 29-42) \\
\hline \multicolumn{4}{|l|}{ Ingredient, $\mathrm{g} / \mathrm{kg}$} \\
\hline Corn & 537.3 & 533 & 561.5 \\
\hline Soybean meal ( $44 \% \mathrm{CP}$ ) & 400 & 396 & 370 \\
\hline Soybean oil & 20 & 35 & 35 \\
\hline Di-calcium (22\% Ca), phosphate $(17 \% \mathrm{P})$ & 19.3 & 17.1 & 15.6 \\
\hline $\mathrm{CaCO}_{3}$ & 10.5 & 8.7 & 8.5 \\
\hline $\mathrm{NaCl}^{3}$ & 3.5 & 3 & 3 \\
\hline Trace mineral premix ${ }^{1}$ & 2.5 & 2.5 & 2.5 \\
\hline Vitamin premix ${ }^{2}$ & 2.5 & 2.5 & 2.5 \\
\hline DL-methionine & 3.1 & 2 & 1.4 \\
\hline L-lysine & 1.3 & - & - \\
\hline \multicolumn{4}{|l|}{ Calculated composition, g/kg } \\
\hline Metabolizable energy, kcal/kg & 2870 & 2980 & 3000 \\
\hline Crude protein & 221 & 220 & 210 \\
\hline Calcium & 8.6 & 7.5 & 7 \\
\hline Available phosphorus & 4.9 & 4.4 & 4.1 \\
\hline Methionine+cysteine & 10.1 & 8.9 & 8 \\
\hline Lysine & 13.3 & 11.9 & 11.3 \\
\hline Threonine & 8.3 & 8.3 & 6.3 \\
\hline Tryptophan & 3.2 & 3.2 & 3 \\
\hline
\end{tabular}

${ }^{1}$ Provided the following per $\mathrm{kg}$ of diet: $\mathrm{Mg}-56 \mathrm{mg} ; \mathrm{Fe}-20 \mathrm{mg} ; \mathrm{Cu}-10 \mathrm{mg} ; \mathrm{Zn}-50 \mathrm{mg}$; Co - $125 \mathrm{mg} ; \mathrm{I}-0.8 \mathrm{mg}$. 2Provided the following per $\mathrm{kg}$ of diet: Vitamin A - 10,000 IU; vitamin $\mathrm{D}_{3}-2000 \mathrm{IU}$; vitamin E - $5 \mathrm{IU}$; vitamin $\mathrm{K}-2 \mathrm{mg}$; riboflavin - $4.20 \mathrm{mg}$; vitamin $\mathrm{B}_{12}-0.01 \mathrm{mg}$; pantothenic acid - $5 \mathrm{mg}$; nicotinic acid - $20 \mathrm{mg}$; folic acid - $0.5 \mathrm{mg}$; choline - $3 \mathrm{mg}$

subtype) for vaccinating broiler chicks and it was injected subcutaneously at 9 days of age. At 28 days of age, 2 birds per replicate were randomly chosen, and blood samples were collected from brachial vein and centrifuged at $3000 \mathrm{~g}$ for $10 \mathrm{~min}$ to obtain serum (SIGMA 4-15 Lab Centrifuge, Germany). Serum antibody titers against AIV were measured by the hemagglutination inhibition test.

At 25 days of age, 8 birds from each treatment group were inoculated via the brachial vein with $1 \mathrm{~mL}$ of a $1 \%$ suspension of sheep red blood cell (SRBC) prepared in phosphate-buffered saline. Blood samples were collected from challenged birds 6 days after and anti-SRBC titers were measured by the microtiter method of Wegmann and Smithies [25]. All titers were expressed as the $\log _{2}$ of the reciprocal of the highest dilution given visible hemagglutination.

\section{Statistical analysis}

The data were subjected to analysis of variance procedures appropriate for a completely randomized design using the general linear model procedures of SAS (SAS Inst., Inc., Cary, NC, USA). Means were compared using Tukey's HSD test. Statistical significance was determined at $\mathrm{p}<0.05$.

\section{Results}

\section{Performance and carcass traits}

Data on performance indices are presented in Table-3. Treatments failed to induce any marked effect on BW of broilers at 14 days of age. AV supplementation at different levels and the antibiotic supplementation significantly $(p<0.05)$ increased BW of broilers at 28 and 42 days of age. Broilers receiving different levels of AV gel had higher daily water consumption compared with other groups during growth period $(\mathrm{p}<0.05)$, but in the other periods, it was not affected. Supplementing drinking water with $1 \%$ AV gel significantly $(\mathrm{p}<0.05)$ increased DFI during the experimental period relative to the control. Water supplemented with different levels of AV significantly $(p<0.05)$ enhanced $F: G$ and DFI during grower period. Broilers receiving flavophospholipol had lower F:G compared with broilers receiving basal diets and normal drinking water during starter, grower, finisher periods, and entire experimental period $(\mathrm{p}<0.05)$. Water supplemented with $0.75 \%$ and $1 \% \mathrm{AV}$ significantly $(p<0.05)$ improved $F: G$ during the entire experimental period compared with broilers fed basal diet and normal drinking.

Table-4 shows carcass and relative organ weights as a percentage of live weight at slaughter. Carcass yield, abdominal fat, liver, gizzard, heart, and proventriculus weights were not significantly affected by the dietary and water treatments, though carcass yield tended to increase in broilers supplemented with $1 \% \mathrm{AV}$ via drinking water or antibiotic in the diet ( $>0.05)$.

\section{Intestinal microflora}

Supplementing drinking water with different levels of $\mathrm{AV}$ or antibiotic in the diet significantly reduced concentration of coliforms, relative to control (Table-5). Maximum concentration of Lactobacilli spp. population reached in broilers supplemented with drinking water containing 1\% AV gel. An improved total Lactobacillus population was noted in groups supplemented with $0.75 \%$ and $1 \%$ AV gel as compared with control and $0.5 \%$ AV gel $(\mathrm{p}<0.05)$. Total Lactobacillus population significantly increased in broilers fed diets containing $4.5 \mathrm{mg}$ flavophospholipol per $\mathrm{kg} \operatorname{diet}(\mathrm{p}<0.05)$. 
Table-3: Effect of antibiotic supplementation in the diet and AV supplementation via drinking water on performance indices of broiler chicks.

\begin{tabular}{|c|c|c|c|c|c|c|}
\hline \multirow[t]{2}{*}{ Item } & \multicolumn{5}{|c|}{ Experimental treatments $^{1}$} & \multirow[t]{2}{*}{ SEM } \\
\hline & Control & $0.5 \%$ AV & $0.75 \%$ AV & $1 \%$ AV & Antibiotic & \\
\hline \multicolumn{7}{|l|}{ BW, g } \\
\hline Day 14 & 368 & 378 & 387 & 381 & 384 & 6.5 \\
\hline Day 28 & $945^{b}$ & $1043^{a}$ & $1072^{\mathrm{a}}$ & $1086^{a}$ & $1075^{a}$ & 21.9 \\
\hline Day 42 & $2190^{b}$ & $2355^{a}$ & $2338^{a}$ & $2417^{a}$ & $2433^{a}$ & 46.1 \\
\hline \multicolumn{7}{|c|}{ Daily feed intake, g/day } \\
\hline Days 1-14 & $36.7^{\mathrm{ab}}$ & $35.5^{b}$ & $36.8^{\mathrm{ab}}$ & $38.3^{\mathrm{a}}$ & $36.7^{\mathrm{ab}}$ & 0.69 \\
\hline Days $15-28$ & $88.9^{b}$ & $95.8^{\mathrm{a}}$ & $95.8^{\mathrm{a}}$ & $96.1^{\mathrm{a}}$ & $92.6^{\mathrm{ab}}$ & 1.97 \\
\hline Days 29-42 & 168 & 179.3 & 172.4 & 179.9 & 174.5 & 3.99 \\
\hline Days 0-42 & $98.1^{\mathrm{b}}$ & $103.5^{\mathrm{ab}}$ & $101.8^{\mathrm{ab}}$ & $104.9^{a}$ & $101.5^{\mathrm{ab}}$ & 1.78 \\
\hline \multicolumn{7}{|c|}{ Daily water consumption, $\mathrm{g} /$ day } \\
\hline Days $1-14$ & 75.5 & 77.8 & 76.7 & 77.4 & 79.9 & 1.57 \\
\hline Days $15-28$ & $187^{\mathrm{b}}$ & $207.4^{\mathrm{a}}$ & $209.4^{a}$ & $208.6^{a}$ & $198.8^{\mathrm{ab}}$ & 5.12 \\
\hline Days 29-42 & 352.9 & 377 & 358 & 385 & 360.9 & 12.67 \\
\hline Days 1-42 & 205.5 & 221.2 & 215.1 & 223.9 & 213.5 & 5.6 \\
\hline \multicolumn{7}{|l|}{$F: G, g: g$} \\
\hline Days 1-14 & $1.71^{\mathrm{a}}$ & $1.59^{c}$ & $1.61^{\mathrm{bc}}$ & $1.70^{\mathrm{ab}}$ & $1.61^{\mathrm{bc}}$ & 0.027 \\
\hline Days $15-28$ & $2.18^{\mathrm{a}}$ & $1.99^{\mathrm{b}}$ & $1.96^{\mathrm{bc}}$ & $1.90^{\mathrm{bc}}$ & $1.87^{c}$ & 0.031 \\
\hline Days 29-42 & $2.01^{a}$ & $2.04^{a}$ & $2.04^{a}$ & $2.02^{a}$ & $1.92^{\mathrm{b}}$ & 0.022 \\
\hline Days 1-42 & $2.01^{a}$ & $1.97^{\mathrm{ab}}$ & $1.95^{\mathrm{b}}$ & $1.94^{b}$ & $1.86^{c}$ & 0.014 \\
\hline
\end{tabular}

a-cMeans in the same row not sharing a common superscript differ $(\mathrm{p}<0.05) .{ }^{1}$ Control: Basal broiler diet and normal drinking water; $0.5 \% \mathrm{AV}: 0.5 \% \mathrm{AV}$ gel in drinking water; $0.75 \% \mathrm{AV}: 0.75 \% \mathrm{AV}$ gel in drinking water; $1 \% \mathrm{AV}: 1 \% \mathrm{AV}$ gel in drinking water; Antibiotic: Basal diet+4.5 mg flavophospholipol $/ \mathrm{kg}$. AV=Aloe vera; SEM=Standard error of mean

Table-4: Effect of experimental treatments on carcass yield and internal relative organ weight of broilers at 42 days of age.

\begin{tabular}{lcccrrr}
\hline Relative organ weight, \% & \multicolumn{3}{c}{ Experimental treatments $^{\mathbf{1}}$} & \multicolumn{1}{c}{ SEM } \\
\cline { 2 - 6 } & Control & $\mathbf{0 . 5 \%}$ AV & $\mathbf{0 . 7 5 \% ~ A V}$ & $\mathbf{1 \%}$ AV & Antibiotic \\
\hline Carcass & 71.5 & 71.2 & 71 & 72.1 & 72.5 & 0.516 \\
Abdominal fat & 1.10 & 1.27 & 1.23 & 0.99 & 1.22 & 0.086 \\
Liver & 2.13 & 2.11 & 2.23 & 2.35 & 2.34 & 0.078 \\
Gizzard & 2.39 & 2.50 & 2.38 & 2.36 & 2.47 & 0.087 \\
Heart & 0.54 & 0.55 & 0.53 & 0.54 & 0.58 & 0.026 \\
Proventriculus & 0.37 & 0.40 & 0.39 & 0.36 & 0.37 & 0.017 \\
\hline
\end{tabular}

$\mathrm{AV}=$ Aloe vera, $\mathrm{SEM}=$ Standard error of mean

Table-5: Effect of experimental treatments on ileum bacteria populations of broiler chicks at 45 days of age. ${ }^{1}$

\begin{tabular}{lcccccr}
\hline Items & \multicolumn{3}{c}{ Experimental treatments } & \multicolumn{2}{c}{ SEM } \\
\cline { 2 - 6 } & Control & $\mathbf{0 . 5 \%} \mathbf{A V}$ & $\mathbf{0 . 7 5 \%} \mathbf{~ A V}$ & $\mathbf{1 \%} \mathbf{A V}$ & Antibiotic & \\
\hline Lactobacilli spp. & $5.84^{\mathrm{c}}$ & $5.89^{\mathrm{c}}$ & $6.33^{\mathrm{b}}$ & $7.69^{\mathrm{a}}$ & $6.32^{\mathrm{b}}$ & 0.098 \\
Coliforms & $5.11^{\mathrm{a}}$ & $4.10^{\mathrm{bc}}$ & $3.97^{\mathrm{c}}$ & $3.89^{\mathrm{c}}$ & $4.07^{\mathrm{bc}}$ & 0.321 \\
\hline
\end{tabular}

a-cMeans in the same row not sharing a common superscript differ $(p<0.05)$. ${ }^{1}$ Results are given as means of groups $(n=4) . A V=$ Aloe vera, SEM=Standard error of mean

\section{Immune responses}

The effect of experimental treatments on antibody titers against influenza virus at day 28 and SRBC at day 30 are presented in Table-6. The treatments had no effect on antibody titer against AIV. Broilers supplemented with $1 \% \mathrm{AV}$ via drinking water showed an improved antibody titer against SRBC compared with those supplemented with basal diet and normal drinking water or basal diet containing antibiotic $(\mathrm{p}<0.05)$.

\section{Discussion}

In this study, broilers receiving antibiotic had higher BW, F:G and total Lactobacillus population and lower concentration of coliforms, relative to broilers receiving basal diets and normal drinking water. Antibiotics may control and inhibit colonization of pathogenic and nonpathogenic species of bacteria in gastrointestinal tract of poultry [26]. A modulated intestinal microflora of broilers could lead to better nutrient utilization, resulting in an increased BW and improved F:G [27]. Results of this experiment indicated that supplementing drinking water with AV gel could induce favorable influences on growth performance and intestinal microflora of broilers. As AV gel has been reported to contain compounds with proven antibacterial [19], antioxidant [28], and immunostimulatory [17] properties; an increase in growth 
Table-6: Effect of antibiotic supplementation in the diet and AV supplementation via drinking water on antibody titers against Newcastle and influenza viruses at 28 days of age and SRBC at 31 days of age.

\begin{tabular}{lccccrr}
\hline Item & \multicolumn{3}{c}{ Experimental treatments } & \multicolumn{2}{c}{ SEM } \\
\cline { 2 - 6 } & Control & $\mathbf{0 . 5 \% ~ A V}$ & $\mathbf{0 . 7 5 \% ~ A V ~}$ & $\mathbf{1 \%} \mathbf{A V}$ & Antibiotic & \\
\hline Influenza $\left(\log _{2}\right)$ & 3.37 & 1.75 & 2.75 & 2.62 & 2.00 & 0.76 \\
SRBC $\left(\log _{2}\right)$ & $7.25^{\mathrm{b}}$ & $7.75^{\mathrm{ab}}$ & $7.75^{\mathrm{ab}}$ & $8.37^{\mathrm{a}}$ & $6.75^{\mathrm{b}}$ & 0.34 \\
\hline
\end{tabular}

a, bMeans in the same row not sharing a common superscript differ $(\mathrm{p}<0.05) . A V=$ Aloe vera, SEM=Standard error of mean, SRBC=Sheep red blood cell

performance was anticipated. Furthermore, AV gel contains several beneficial ingredients including vitamins, minerals, enzymes, organic acids, and carbohydrates which could improve performance criteria of broilers [29]. The results of this trial indicated that supplementation of AV gel to drinking water seem to have an affirmative influence on BW via higher DFI. Similar results were found in the research conducted by Olupona et al. [30]. They investigated the effect of supplementation of AV gel in drinking water on broiler performance and observed that the final BW improved via higher DFI. In another study in broilers, Darabighane et al. [31] reported that broilers fed dietary supplemented with $1.5 \%, 2 \%$ and $2.5 \%$ AV gel indicated higher DFI and BW than those fed basal diets. They also observed that $2 \%$ AV gel significantly enhanced villus height to crypt depth ratio in comparison with antibiotic group. Odo et al. [32] and Mmereole [33] also reported that inclusion of AV leaves in broiler feed increased BW compared with the control. Likewise, Changkang et al. [34] indicated that $600 \mathrm{mg}$ of $\mathrm{AV}$ gel water extract added in broiler feed resulted in significant increase of BW in the $3^{\text {rd }}$ and $6^{\text {th }}$ weeks, in comparison with the control. In contrast, Mehala and Moorthy [35] assessed $0.1 \%$ and $0.2 \% \mathrm{AV}$ powder and reported no effects on DFI, BW, and $\mathrm{F}: \mathrm{G}$ in broilers.

In the present trial, the affirmative impact of AV gel on the F:G can be related to more balanced biota population in the chicks' gut. As medicinal plants and their properties may control and inhibit colonization of pathogenic and nonpathogenic species of bacteria in gastrointestinal tract of poultry. This may lead to a more efficient use of nutrients, resulting in increased growth and improved F:G [27]. The effect of AV gel on microflora composition is related to the polysaccharides specially acemannan which behave similar to prebiotics [21]. Furthermore, acemannan has been reported to have indirect antimicrobial activity by its ability to stimulate macrophages [36]. AV gel has been shown to have bactericidal activity against a wide range of Gram-negative and positive bacteria such as S. aureus, Streptococcus pyogenes, E. coli, and Salmonella Typhi [37]. Lin et al. [38] indicated that AV gel powder, Aloe polysaccharides, and acemannan could significantly reduce the cecal contents of $E$. coli and increased cecal bifidobacteria and lactic acid bacteria concentration. The reduced count of coliforms observed in the broilers received AV gel was related to the increased counts of Lactobacilli. In fact, Lactobacilli compete with pathogens for nutrients and sites of intestinal adhesion [39]. Another beneficial activity of Lactobacilli is synthesis of bacteriocin [40]. Lactic acid and acetic acid, which are formed by the fermentation of Lactobacilli, could limit the growth and colonization of pathogenic bacteria in chicks' gut [39]. Results of the present research confirmed those obtained by Heggers et al. [19], Ferro et al. [41], Shilpakala et al. [20], and Saritha et al. [42].

In this trial, carcass yield and internal organ weight were not markedly affected by experimental treatments. Our findings are consistent with those reported by Silalahi et al. [43] who did not find any differences among the control treatment and those containing dried or fresh $\mathrm{AV}$ gels on carcass traits. However, in another trial, the percentage of carcass and breast were affected by AV juice application through drinking water [30]. In accord to our results, several studies have shown that addition of antibiotic to the broiler's diets and had not any marked effect on carcass traits $[1,44,45]$.

So far, antibody responses have been used as measures of humoral immune status of birds. The treatments had no effect on antibody titer against AIV. The reason might be related to the type of applied vaccine which was inactivated and/or vaccination date. Antibody titer against SRBC increased in the group treated with $1 \% \mathrm{AV}$ in drinking water compared with those on the control and flavophospholipol diets. Similarly, Akhtar et al. [46] reported significantly higher anti-SRBC antibody (total immunoglobulins [Igs], IgG and IgM) titers in chickens supplemented with ethanolic extract of AV as compared with the control group. Results of another trial revealed significantly higher humoral immune responses against SRBC and NDV in chickens supplemented with $2.5 \%$ $\mathrm{AV}$ gel in diet [47]. Likewise, Valle-Paraso et al. [48] demonstrated significant increase in NDV antibody titers and absolute counts of monocytes, lymphocytes, and heterophils in broilers received $2 \%$ extract of AV gel in drinking water compared with control. Several studies in broilers have also confirmed that Aloe and its extract can enhance immune response and specific antibody levels [34,38,49]. Acemannan, a major polysaccharide present in $\mathrm{AV}$ gel, appeared to be able to activate macrophages via binding to mannose receptors. Acemannan activates macrophages to 
release cytokines such as IL-1, IL- 6 and TNF- $\alpha$, thus leading to an increase in the number and function of cytotoxic T-cells $[17,50]$. The acemannan, was also shown to increase nitric oxide production by macrophages, and upregulate phagocytic and candidacidal activities [18,51]. The immune enhancing effect of acemannan is also mentioned to be due to the induced maturation of immature dendritic cells, which are the important accessory cells for the initiation of primary immune response [52]. Moreover, Chinnah et al. [53] found that acemannan has strong adjuvant properties in vaccination against avian viral diseases such as NDV and Marek's disease.

\section{Conclusion}

These findings demonstrated a possibility of supplementing broiler drinking water with $1 \% \mathrm{AV}$ gel as an alternative for AGP substitution.

\section{Authors' Contributions}

MS, MT, and GG have designed the plan of work. MS and NL carried out the laboratory work and analyzed the results. MS and NL drafted and revised the manuscript. All authors read and approved the final manuscript.

\section{Acknowledgments}

The authors gratefully acknowledge Barij Essence Pharmaceutical Company for supplying AV gel for this study. This study was supported by Islamic Azad University, Isfahan Branch, and resulted from M.Sc. thesis of Meisam Shokraneh (grant number: 854).

\section{Competing Interests} interests.

The authors declare that they have no competing

\section{References}

1. Landy, N., Ghalamkari, G.H. and Toghyani, M. (2012) Evaluation of St John's wort (Hypericum perforatum L.) as an antibiotic growth promoter substitution on performance, carcass characteristics, some of the immune responses, and serum biochemical parameters of broiler chicks. J. Med. Plants Res., 6: 510-515.

2. Landy, N. and Kavyani, A. (2014) Effect of using multistrain probiotic on performance, immune responses, and cecal microflora composition in broiler chickens reared under heat stress condition. Iran. J. Appl. Anim. Sci., 3: 703-708.

3. Wati, T., Ghosh, T.K., Syed, B. and Haldar, S. (2015) Comparative efficacy of a phytogenic feed additive and an antibiotic growth promoter on production performance, caecal microbial population and humoral immune response of broiler chickens inoculated with enteric pathogens. Anim. Nutr., 1: 213-219.

4. Miles, R.D., Butcher, G.D., Henry, P.R. and Littell, R.C. (2006) Effect of antibiotic growth promoters on broiler performance, intestinal growth parameters, and quantitative morphology. Poult. Sci., 85: 476-485.

5. Singer, R.S. and Hofacre, C.L. (2006) Potential impacts of antibiotic use in poultry production. Avian Dis., 50: 161-172.

6. Goodarzi, M., Nanekarani, S.H. and Landy, N. (2014) Effect of dietary supplementation with onion (Allium cepa L.) on performance, carcass traits and intestinal microflora composition in broiler chickens. Asian Pac. J. Trop. Dis., 4: S297-S301.

7. Ghalamkari, G.H., Toghyani, M., Landy, N. and Tavalaeian, E. (2012) Investigation the effects using different levels of Mentha pulegium L. (pennyroyal) in comparison with an antibiotic growth promoter on performance, carcass traits and immune responses in broiler chickens. Asian Pac. J. Trop. Biomed., 2: S1396-S1399.

8. Andremont, A. (2000) Consequences of antibiotic therapy to the intestinal ecosystem. Ann. Fr. Anesth., 19: 395-402.

9. Yazdi, F.F., Ghalamkari, G.H., Toghiani, M., Modaresi, M. and Landy, N. (2014a) Anise seed (Pimpinella anisum L.) as an alternative to antibiotic growth promoters on performance, carcass traits and immune responses in broiler chicks. Asian Pac. J. Trop. Dis., 4: 447-451.

10. Yazdi, F.F., Ghalamkari, G.H., Toghiani, M., Modaresi, M. and Landy, N. (2014b) Efficiency of Tribulus terrestris L. as an antibiotic growth promoter substitute on performance and immune responses in broiler chicks. Asian Pac. J. Trop. Dis., 4 Suppl 2: S1014-S1018.

11. Nanekarani, S., Goodarzi, M., Heidari, M. and Landy, N. (2012) Efficiency of ethanolic extract of peppermint (Mentha piperita) as an antibiotic growth promoter substitution on performance, and carcass characteristics in broiler chickens. Asian Pac. J. Trop. Biomed., 2: S1-S4.

12. Toghyani, M., Mosavi, S.K., Modaresi, M. and Landy, N. (2015) Evaluation of kefir as a potential probiotic on growth performance, serum biochemistry and immune responses in broiler chicks. Anim. Nutr., 1: 305-309.

13. Vogler, B.K. and Ernst, E. (1999) Aloe vera: A systematic review of its clinical effectiveness. Br. J. Gen. Pract., 49: 823-828.

14. Boudreau, M.D. and Beland, F.A. (2006) An evaluation of the biological and toxicological properties of Aloe barbadesis (Miller), Aloe vera. J. Environ. Sci. Health, 24: 103-154.

15. Hamman, J.H. (2008) Composition and applications of Aloe vera Leaf gel. Molecules, 13: 1599-1616.

16. Du, X., Chen, X., Zhao, B., Lv, Y., Zhang, H., Liu, H., Chen, Z., Chen, Y. and Zeng, X. (2011) Astragalus polysaccharides enhance the humoral and cellular immune responses of hepatitis B surface antigen vaccination through inhibiting the expression of transforming growth factor $\beta$ and the frequency of regulatory T cells. FEMS. Immunol. Med. Microbiol., 63: 228-235.

17. Zhang, L. and Tizard, I.R. (1996) Activation of a mouse macrophage cell line by acemannan: The major carbohydrate fraction from Aloe vera gel. Immunopharmacology, 35: 119-128.

18. Djeraba, A. and Quere, P. (2000) In vivo macrophage activation in chickens with Acemannan, a complex carbohydrate extracted from Aloe vera. Int. J. Immunopharmacol., 22: 365-372.

19. Heggers, J.P., Pineless, G.R. and Robson, M.C. (1979) Dermaide Aloe/Aloe vera gel comparison of the antimicrobial effects. J. Am. Med. Technol., 41: 293-294.

20. Shilpakala, S.R., Prathiba, J. and Malathi, R. (2009) Susceptibilities of Escherichia coli and Staphylococcus aureus to Aloe barbadensis. Eur. Rev. Med. Pharmacol., 13: 461-464.

21. Darabighane, B. and Nahashon, S.N. (2014) A review on effects of Aloe vera as a feed additive in broiler chicken diets. Ann. Anim. Sci., 14: 491-500.

22. Feng, Y.Z., Gu, F.X., Yuan, Z.X., Zhang, Y.J., Liu, S.H., Hu, L.L. and Xu, L. (2011) Effects of Aloe polysaccharide on immune organ index and immune efficacy of vaccine against Newcastle disease in broiler. J. Henan Agric. Univ., 45: 432-436.

23. Aviagen. (2014) Ross Broiler Management Manual. Aviagen Ltd., Midlothian, UK.

24. Smits, C.H., Veldman, A., Verkade, H.J. and Beynen, A.C. (1998) The inhibitory effect of carboxymethylcellulose 
with high viscosity on lipid absorption in broiler chickens coincides with reduced bile salt concentration and raised microbial numbers in the small intestine. Poult. Sci., 77: 1534-1539.

25. Wegmann, T.G. and Smithies, O. (1966) A simple hemagglutination system requiring small amounts of red cells and antibodies. Transfusion, 6: 67-75.

26. Sun, Y. and O'Riordan, M.X. (2013) Regulation of bacterial pathogenesis by intestinal short-chain fatty acids. Adv. Appl. Microbiol., 85: 93-118.

27. Bedford, M. (2000) Removal of antibiotic growth promoters from poultry diets. World Poult. Sci. J., 56: 347-365.

28. Rajasekaran, S., Sivagnanam, K. and Subramanian, S. (2005) Antioxidant effect of Aloe vera gel extract in streptozotocin-induced diabetes in rats. Pharmacol. Rep., 57: 90-96.

29. Yim, D., Kang, S.S., Kim, D.W., Kim, S.H., Lillehoj, H.S. and Min, W. (2011) Protective effects of Aloe vera-based diets in Eimeria maxima-infected broiler chickens. Exp. Parasitol., 127: 322-325.

30. Olupona, J.A., Omotoso, O.R., Adeyeye, A.A., Kolawole, O.D., Airemionkhale, A.P. and Adejinmi, O.O. (2010) Effect of Aloe vera Juice Application through Drinking Water on Performance, Carcass Characteristics, Hematology and Organoleptics Properties in Broilers. Congress Annual Meeting. North Carolina, USA. Vol. 98. p42-43.

31. Darabighane, B., Zarei, A., Shahneh, A.Z. and Mahdavi, A. (2011) Effects of different levels of Aloe vera gel as an alternative to antibiotic on performance and ileum morphology in broilers. Ital. J. Anim. Sci., 10: 189-194.

32. Odo, B.I., Ekenyem, B.U. and Nwamo, A.C. (2010) Effect of Aloe vera leaf protein concentrate on growth performance of cockerels. Int. J. Poult. Sci., 9: 426-428.

33. Mmereole, F.U.C. (2011) Evaluation of the inclusion of Aloe vera as an alternative to antibiotic growth promoter in broiler production. Pak. J. Nutr., 10: 1-5.

34. Changkang, W., Hong-Qiang, J., Jian-Ming, T., WeiWei, G., Ren-Na, S. and Qi, Z. (2007) Effect of Aloe powder and extract on production performance and immune function of broiler chickens. J. Fujian. Agric. Forest. Univ., 36: 614-617.

35. Mehala, C. and Moorthy, M. (2008) Production performance of broilers fed with Aloe vera and Curcuma longa (turmeric). Int. J. Poult. Sci., 7: 852-856.

36. Cock, I.E. (2008) Antimicrobial activity of Aloe barbadensis Miller leaf gel components. Int. J. Microbiol., 4: 2.

37. Tambekar, D.H., Khante, B.S., Deb, S. and Dahikar, S.B. (2007) Studies on antibacterial potential of Aloe vera fresh gel, latex, and commercially available powders. Nat. Prod., 3: 73-76.

38. Lin, J., Zhang, F.Y., Xu, Y., Ting, Z.X. and Po, Y.D. (2005) Effects of gel, polysaccharide and acemannan from Aloe vera on broiler gut flora, microvilli density, immune function and growth performance. Chin. J. Vet. Sci., 25: 668-671.

39. Park, B.S. (2011) Effects of pitamin on growth performance, carcass characteristics and cecal microflora of broiler chicken. J. Environ. Biol., 32: 585-590.

40. Joerger, R.D. (2003) Alternatives to antibiotics:
Bacteriocins, antimicrobial peptides and bacteriophages. Poult. Sci., 82: 640-647.

41. Ferro, V.A., Bradbury, F., Cameron, P., Shakir, E., Rahman, S.R. and Stimson, W.H. (2003) In vitro susceptibilities of Shigella flexneri and Streptococcus pyogenes to inner gel of Aloe barbadensis Miller. Antimicrob. Agents Chem., 47: 1137-1139.

42. Saritha, V., Anilakumar, K.R. and Farhath, K.H. (2010) Antioxidant and antibacterial activity of Aloe vera gel extracts. Int. J. Pharm. Biol. Arch., 1: 376-384.

43. Silalahi, M., Hardjosworo, P.S., Sinurat, A.P. and Purwadaria, T. (2011) Use of dried and fresh Aloe vera barbadens as feed supplements and their effect on broiler performance. Anim. Prod., 11: 53-58.

44. Landy, N., Ghalamkari, G.H. and Toghyani, M. (2011a) Performance, carcass characteristics, and immunity in broiler chickens fed dietary neem (Azadirachta indica) as alternative for an antibiotic growth promoter. Livest. Sci., 142: 305-309.

45. Landy, N., Ghalamkari, G.H., Toghyani, M. and Moattar, F. (2011b) The effects of Echinacea purpurea L. (purple coneflower) as an antibiotic growth promoter substitution on performance, carcass characteristics and humoral immune response in broiler chickens. J. Med. Plants Res., 5: 2332-2338.

46. Akhtar, M., Hai, A., Muhammad Awais, M., Iqbal, Z., Muhammad, F., Haq, A. and Anwar M.I. (2012) Immunostimulatory and protective effects of Aloe vera against coccidiosis in industrial broiler chickens. Vet. Parasitol., 186: 170-177.

47. Darabighane, B., Zarei, A. and Shahneh, A.Z. (2012) The effects of different levels of Aloe vera gel on ileum microflora population and immune response in broilers: A comparison to antibiotic effects. J. Appl. Anim. Res., 40: 31-36.

48. Valle-Paraso, M.G.R., Vidamo, P.J.S., Anunciado, R.V.P. and Lapitan, A.M. (2005) Effects of Aloe vera (Aloe barbadensis) on the white blood cell count and antibody titre of broiler chickens vaccinated against Newcastle disease. Philipp. J. Vet. Med., 42: 49-52.

49. Xuemei, W. and Xiaochun, L. (2008) Effects of Aloe polysaccharides on the production performance and immune function in broiler. Chin. Feed, 19: 27-29.

50. Cooper, J.C. and Turcasso, N. (1999) Immunostimulatory effects of beta-1, 3-glucan and acemannan. J. Am. Nutraceutical. Assoc., 2: 5-10.

51. Stuart, R.W., Lefkowitz, D.L., Lincoln, J.A., Howard, K., Gelderman, M.P. and Lefkowitz, S.S. (1997) Upregulation of phagocytosis and candidicidal activity of macrophages exposed to the immunostimulant acemannan. Int. J. Immunopharmacol., 19: 75-82.

52. Lee, J.K., Lee, M.K., Yun, Y.P., Kim, Y., Kim, J.S., Kim, Y.S., Kim, K., Han, S.S. and Lee, C.K. (2001) Acemannan purified from Aloe vera induces phenotypic and functional maturation of immature dendritic cells. Int. Immunopharmacol., 1: 1275-1284.

53. Chinnah, A.D., Baig, M.A., Tizard, I.A. and Kemp, M.C. (1992) Antigen dependent adjuvant activity of a polydispersed $\beta-(1,4)$-linked acetylated mannan (acemannan). Vaccine, 10: 551-554. 